\title{
Conflict of interest guidelines for clinical guidelines
}

\section{We need a culture of transparency and disclosure for effectively managing conflicts}

linical guidelines are increasingly important in medical practice, but declarations of conflicts of interest have been neglected. The influence that corporate involvement may exert on clinical judgement appears to have been especially overlooked. ${ }^{1}$ Compliance with guidelines may be regarded as a measure of quality of care and can influence doctors' remuneration, ${ }^{2-5}$ via incentive programs. We argue for changes to current practice in the development and publication of clinical guidelines.

\section{Methodology}

We identified organisations that were primarily responsible for developing five or more clinical guidelines listed by the National Health and Medical Research Council (NHMRC) on 14 April 2011. ${ }^{6}$ We reviewed over 200 guidelines to ascertain whether they had a conflict of interest (COI) statement. When the guideline contained a conflict declaration, we reviewed whether information was presented about the nature of the conflict and whether there was an account of processes used to manage conflicts. Guidelines that were not about medications, equipment or testing were excluded. Neither sponsorship acknowledgement nor the presence of a logo were regarded as a declaration of conflict, nor were statements that "members signed a COI statement" with no further details. Our results are summarised in Box 1.

\section{Importance of clinical guidelines}

Clinical guidelines for major diseases are being promoted with increasing vigour by medical organisations and health authorities. In Australia, the NHMRC clinical practice guideline portal contains more than 470 guidelines covering 25 disease groups. ${ }^{6}$

Confidence in the evidence base of guidelines is necessary for uptake by doctors and to promote quality of care. At their best, guidelines convert evidence into an "ideal practice" guide, driving scientific evidence to the clinical coalface. They can be used to monitor and improve care, reduce differences in care, and make complex evidence usable to doctors who are not expert in an area.

... If you can talk with crowds and keep your virtue, Or walk with kings - nor lose the common touch; If neither foes nor loving friends can hurt you;

If all men count with you, but none too much ... from /f, by Rudyard Kipling

\section{Summary}

- Clinical guidelines are being increasingly produced to improve quality of care, but are vulnerable to bias.

- Only $15 \%$ of guidelines on the National Health and Medical Research Council portal from the most prolific developers have published conflict of interest statements, and fewer detail the processes used to manage conflicts.

- Comprehensive disclosure of conflicts is needed to safeguard the integrity of clinical guidelines and the medical profession.

- Peak bodies and clinicians should seek to promote an improvement to current poor practice.

Governments have a compelling interest in guidelines that represent only evidence-based research, unaffected by competing interests. Underresourced health authorities must have confidence that appropriate medications and practices are recommended. The inclusion of more expensive but less efficacious medications can incur significant cost because of the exponential gearing effect that guidelines may have. For example, Eli Lilly sparked a controversy by funding the development of "Surviving sepsis" guidelines while conducting a sophisticated campaign for clinicians to advocate for greater access to activated protein $\mathrm{C}$ in treatment, and while having financial ties with a number of guideline authors. ${ }^{7}$

\section{Sources of conflict}

Michael J Williams* BA(Hons), LLB(Hons), Research Assistant, Michael Kirby Centre for Public Health and Human Rights ${ }^{1}$

Dev A S Kevat* MB BS, LLB(Hons), $\mathrm{MPH}(\mathrm{Oxon}), \mathrm{PhD}$ Candidate, Critical Care Research,'Registrar ${ }^{2}$

Bebe Loff LLB, MA (Lond), PhD, Director ${ }^{1}$

1 School of Public Health and Preventive Medicine, Monash University, Melbourne, VIC.

2 Royal Brisbane and Women's Hospital, Brisbane, QLD.

*Equal first authors

michael.williams@ monash.edu dev.kevat@monash.edu

MJA 2011; 195: 442-445 doi: 10.5694/mja10.11130
A COI occurs when "a set of conditions in which professional judgment concerning a primary interest (such as a patient's welfare or the validity of research) tends [or has the potential] to be unduly influenced by a secondary interest (such as financial gain) ${ }^{\prime} .{ }^{8}$ COIs can arise through the acts of individuals, institutions and professional bodies; the most common are authors having financial links with industry, including being paid consultancies or honoraria, or holding company shares. Conscious, wilful manipulation of guideline content is likely to be rare; undeclared and poorly managed conflicts are likely to be more common.

Both financial and non-financial conflicts are problematic. Non-financial conflicts may include serving as a board member or having a spouse in the employ of a pharmaceutical company. The Lancet's statements on COIs are lucid and practical. The journal refuses to publish authors who:

... within the past 3 years, and with a relevant company or competitor, has any stocks or shares, equity, contract of employment, or a named position on a company board; holds (or is applying for) a relevant patent; or has received (or will do) a fee from any organisation other 
Guideline developer

\begin{tabular}{|c|c|c|c|}
\hline Andrology Australia & $0 / 6(0 \%)$ & na & na \\
\hline Australasian Society for HIV Medicine & $0 / 7(0 \%)$ & na & na \\
\hline Australasian Society for Infectious Diseases & $4 / 7(57 \%)$ & $<50 \%$ & $<50 \%$ \\
\hline Australian Cancer Network & $5 / 7(71 \%)$ & $<50 \%$ & $<50 \%$ \\
\hline Australian Resuscitation Council & $0 / 24(0 \%)$ & na & na \\
\hline Cardiac Society of Australia and New Zealand & $0 / 5(0 \%)$ & na & na \\
\hline Caring for Australasians with Renal Impairment* & $\sim 7 / 12(\sim 58 \%) *$ & $<50 \%$ & na \\
\hline Department of Health and Human Services Tasmania & $0 / 9(0 \%)$ & na & na \\
\hline Diabetes Australia & $0 / 6(0 \%)$ & na & na \\
\hline Drug and Alcohol Services South Australia & $0 / 5(0 \%)$ & na & na \\
\hline Heart Foundation & $3 / 5(60 \%)$ & $<50 \%$ & $<50 \%$ \\
\hline Joanna Briggs Institute & $0 / 8(0 \%)$ & na & na \\
\hline National Asthma Council Australia & $0 / 3(0 \%)$ & na & na \\
\hline National Breast and Ovarian Cancer Centre ${ }^{\dagger}$ & $0 / 8(0 \%)$ & na & na \\
\hline New South Wales Department of Health & $2 / 43(5 \%)$ & na & na \\
\hline NSW Therapeutic Advisory Group & $3 / 4(75 \%)$ & $100 \%$ & $<50 \%$ \\
\hline Queensland Health & $2 / 5(40 \%)$ & na & na \\
\hline $\begin{array}{l}\text { Queensland Maternity and Neonatal Clinical } \\
\text { Guidelines Program }\end{array}$ & $0 / 14(0 \%)$ & na & na \\
\hline Royal Australian College of General Practitioners & $2 / 7(29 \%)$ & $100 \%$ & $<50 \%$ \\
\hline Therapeutic Guidelines & $\begin{array}{c}12 / 12 \text { (no institutional conflicts) } \\
0 / 12 \text { (no COl declarations from individuals) }\end{array}$ & na & $100 \%$ \\
\hline
\end{tabular}

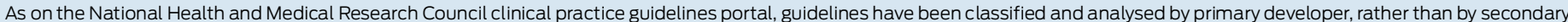

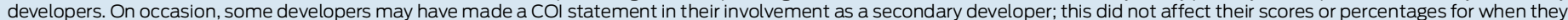
were primary developers. It is our view that primary developers have overall responsibility for managing the COI process.

$\mathrm{COI}=$ conflict of interest. na = not applicable (no declared conflicts). * The 12 Caring for Australasians with Renal Impairment (CARI) guidelines were made up of more

than 50 components, which were analysed individually. The great majority of CARI COI statements referred to having no COI, as on the CARI Guidelines for declaring COI

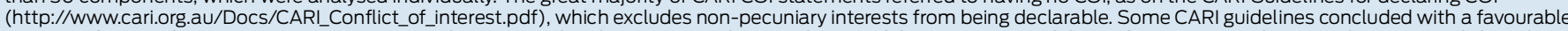

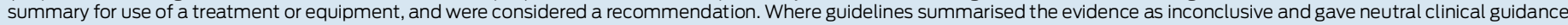

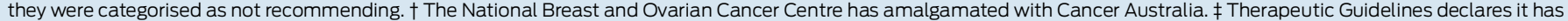

no institutional industry ties and no institutional COIs.

than The Lancet or its review journals to write, be named on, or to submit the paper. Financial COIs that are not exclusions to commissioning or considering spontaneously submitted items, but must be declared in the published paper, are: consultancies, honoraria, speakers' fees; research funding or funding for equipment or drugs; travel or accommodation payments; or expert testimony fees. We have not introduced a financial cut-off such as US\$10000 because we do not accept that there is a universally agreed sum of money that if exceeded will result in bias. ${ }^{9}$

In summary: "Is there anything ... that would embarrass you if it were to emerge after publication and you had not declared it?"10

Effective management of conflicts depends on individual attributes (such as self-awareness) and institutional management processes. Conflicts may have an institutional source if significant corporate funding is received and staff participate in related guideline development. Good practices are particularly necessary to manage institutional conflicts, as individuals in those instances may be less likely to perceive or declare a conflict.

\section{Disclosure and transparency}

Guidelines are valuable and vulnerable. Our review of the country's most prolific guideline developers shows that only $15 \%$ of guidelines have COI statements (Box 1 ). This raises questions about whether medical bodies are affected by unrecognised, and thus unaddressed, extraneous interests, and may erode the trust the community has in the profession ${ }^{11}$ to speak authoritatively about health problems.

A recent study of 313 Australian clinical guidelines used between 2003 and 2007 found that almost $80 \%$ had no competing interest statement. ${ }^{12}$ This lack of disclosure is inexplicably inconsistent with practices adopted by peerreviewed journals and with guidelines for participation in meetings of some medical organisations. ${ }^{13}$ Rates of conflict disclosure on guidelines are so low that, at best, they may indicate that the profession is in a "precontemplative" phase, oblivious to the existence or extent of the issue.

We were unable to quantify total sponsorship from pharmaceutical companies to guideline-developing bodies as institutions and to individuals on guideline-drafting panels. While organisations often disclose corporate supporters on their websites, information on how much is donated and where it is directed is neither easily accessible nor comprehensive. In some cases, the websites of pharmaceutical companies are more informative than developers' websites. For example, Pfizer Australia declares on its website a donation of \$150 000 in 2010 towards the Heart Foundation's Career Development Fellowship. ${ }^{14}$ However, there is no corresponding 
2 Proposed six-step process for improving conflict of interest disclosure

Guidelines already released

1. After consultation with drafting panels, guideline developers should publish conflict of interest (COI) statements for guidelines where possible. Future copies of guidelines should have these COI statements included in the guidelines document or on a referred website.

2. Developers should make public whatever COI management processes they currently use.

3. The National Health and Medical Research Council (NHMRC) should list whether guidelines contain a COI statement (other characteristics are already listed by the NHMRC on individual "guideline detail" pages).

\section{To improve future guidelines}

4. Developers should formulate a process for dealing with COIs in guideline development or improve existing processes. An outline of these processes should then be made available online for public feedback, and known interested parties should be notified. After finalisation, the outline should be made publicly accessible.

5. For individual guidelines, developers should have a COI

declaration that:

details the pecuniary, personal and professional benefits received by developers and drafting committee members;

- includes a statement that any benefits received have not influenced their professional opinion; and

- contains information on how key conflicts were resolved for each instance, for example "sponsored individual excluded from certain discussions concerning treatments and final guideline recommendations" or "sponsorship received 4 years ago". 6. The NHMRC should prioritise the provision of updated advice on appropriate management and disclosure of COls in guideline development.

statement on the Heart Foundation website or in its annual reports. ${ }^{15}$ One must consult the 2011 Fellowship Application Guide to learn that "Funds may be available from member companies of the Heart Foundation Pharmaceutical Roundtable to support several Research Awards each year". ${ }^{16}$ The Guide lists the corporations that constitute the Roundtable, including Pfizer, but does not specify the amount Pfizer provides. ${ }^{17}$ Pharmaceutical sponsorship of medical research and professional bodies is considerable, raising the spectre of influence, which should be unequivocally confronted by the profession. ${ }^{18}$

\section{Developing sound processes}

It is insufficient for developers to claim to have internal processes for conflict management, which they do not outline. The benefit of having a published COI statement is that it allows medical and non-medical audiences to consider biases developers may have, and seek other evidence when warranted. We propose a six-step process (Box 2) to improve the transparency of guideline development. We further propose that guideline developers should publicly outline the processes by which they manage conflicts. Conflict statements for guidelines should inform the reader about the nature of competing interests and how they were managed.

Developers of guidelines may adopt a number of strategies, including the following:

- A period of 3 years from when industry assistance was last received may be regarded as sufficient time for the conflict to have lost its potential for "undue influence" and allow researchers to resume their places on drafting committees (with all past benefits still being declared).

- The structure of drafting panels could be tiered, and those with a competing interest would only discuss or draft certain sections of the guidelines (eg, sections relating to the nature of the disease), while those without a competing interest might be responsible for writing sections on treatments.

- Some researchers may contribute to guidelines at early stages with the final product prepared by those without competing interests, as rigorous processes to manage conflicts may restrict the participation of prominent figures with extensive links to industry. ${ }^{18}$

- The committee chair may be an individual who has not received industry benefits and could have the final decision on recommendations concerning treatment options.

In the United States, the National Institutes of Health $(\mathrm{NIH})$ have detailed and instructive rules to manage COIs for employees (Box 3). The suggestion that conflict management processes be public is an additional requirement.

There may be some advantage if independent, statutory bodies produce future guidelines ${ }^{20}$ and other groups cease independent guideline development. In the United Kingdom, the National Institute for Health and Clinical Excellence (NICE) is part of the National Health Service and is the main body for clinical guideline development. The Australian Commission on Safety and Quality in Health Care or the NHMRC National Institute of Clinical Studies could assume a similar role, though this would require government funding. This seems unlikely given the current outsourced model that - despite its flaws - costs the government little.

Placing statutory bodies in charge of guideline development may prevent institutional-level conflicts, but not those of individual panel members. NICE has a policy encompassing many types of financial and non-financial interests. $^{21}$ The policy provides that committee heads with financial conflicts should not take part in guideline development. ${ }^{22}$ The COIs are recorded in minutes that are accessible on the internet, and a COI register is accessible on request. An increasing number of conflict statements are now included in the guidelines themselves.

The NHMRC key principles for developing guidelines do not mention the management of COIs. ${ }^{23}$ The NHMRC standards and procedures for externally developed guidelines refers to the issue, asking that drafting groups disclose their COIs, but is silent on the need to publicly disclose conflicts and how they are managed. ${ }^{24}$ The NHMRC must urgently promote a more ethically sound development

3 Some prohibited activities for National Institutes of Health employees to manage conflicts of interest in human subjects research ${ }^{19}$

- Serving as a director, officer or decisionmaker for a research sponsor

- Holding stock or options in a commercial sponsor unless below the minimum or in an independently managed, diversified fund

- Receiving honoraria from a commercial sponsor

- Having other personal or outside relationships with a commercial sponsor

- Having financial interest above the minimum in companies with similar products known to the investigator to be competing with the product under study

- Participating in an institutional review board or data safety and monitoring board decision with the potential to affect a spouse's employer 
process for guidelines. It should be a condition of NHMRC guideline approval that competing interest declarations and processes are made public. This would be consistent with the NHMRC's rigorous process of conflict management in the evaluation of research grant applications - it is no lesser cause nor fewer dollars that are at stake in the development of clinical guidelines.

Finally, although the pendulum must swing towards greater transparency, this must be balanced against the risk that overly onerous obligations become a disincentive to participation in guideline development. It is important to establish a culture of disclosure and sound management of conflicts rather than attempting to implement a standard that cannot be met. As Tim Kendall of NICE has said, "It's hard to find clinicians for guidelines who don't have some COIs. We think it's important that the guideline process is open and transparent". ${ }^{25}$

Acknowledgements: We thank John McNeil, Monash University, for helpful comments and Jack Fuller, University of Oxford, for poetic assistance.

Competing interests: No relevant disclosures.

Provenance: Not commissioned; externally peer reviewed.

1 Choudry NK, Stelfox HT, Detsky AS. Relationships between authors of clinical practice guidelines and the pharmaceutical industry. JAMA 2002; 287: 612-617.

2 Lippi Bruni M, Nobilio L, Ugolini C. Economic incentives in general practice: the impact of pay-for-participation and pay-for-compliance programs on diabetes care. Health Policy 2009; 90: 140-148.

3 National Institute for Health and Clinical Excellence. Secondary prevention in primary and secondary care for patients following a myocardial infarction, Clinical Guideline 48. London: NICE, 2007. http://guidance.nice.org.uk/CG48 (accessed Aug 2011).

4 National Institute for Health and Clinical Excellence. Ouality and Outcomes Framework menu of indicators. Indicator NM07 QOF ID: CHD14. London: NICE, 2010. http://www.nice.org.uk/aboutnice/qof/indicators_detail.jsp?summary= 13071 (accessed Sep 2011).

5 British Medical Association. Focus on QOF payments 2011. London: BMA, 2007. http://www.bma.org.uk/employmentandcontracts/independent_ contractors/quality_outcomes_framework/FocusQOF0207.jsp (accessed Aug 2011)

6 National Health and Medical Research Council. Clinical practice guidelines portal. Canberra: NHMRC, 2011. http://www.clinicalguidelines.gov.au/ browse.php?pageType=3\&Submit=Go (accessed Aug 2011)

7 Eichacker PQ, Natanson C, Danner RL. Surviving sepsis - practice guidelines, marketing campaigns, and Eli Lilly. NEngl J Med 2006; 355: 1640-1642.

8 Thompson DF. Understanding financial conflicts of interest. NEngl J Med 1993; 329: 573-576.
9 James A, Horton R, Collingridge D, et al. The Lancet's policy on conflicts of interest - 2004. Lancet 2004: 363: 2-3.

10 Horton R. A statement by the editors of The Lancet. Lancet 2004: 363: 820821.

11 Hardie EA, Critchley CR. Public perceptions of Australia's doctors, hospitals and health care systems. Med J Aust 2008; 189: 210-214.

12 Buchan H, Currie KC, Lourey EJ, Duggan GR. Australian clinical practice guidelines - a national study. Med J Aust 2010; 192: 490-494.

13 The Royal Australian College of General Practitioners. Conflict of interest policy. Melbourne: RACGP, 2009. http://www.racgp.org.au/scriptcontent/ poicy/policy_council/RACGPcouncilConflictofInterestformforCommittees.pdf (accessed Aug 2011).

although the

pendulum must

swing towards

greater

transparency,

this must be

balanced

against the risk

that overly

onerous

obligations

become a

disincentive to

participation
14 Pfizer Australia. Partnerships. West Ryde: Pfizer Australia, 2010. http:// pfizer.com.au/sites/au/about_pfizer_Australia/our_partnerships/Pages/ TheHeartFoundation.aspx (accessed Aug 2011).

15 Heart Foundation. Information for professionals. Melbourne: Heart Foundation, 2011. http://www.heartfoundation.org.au/Information-forprofessionals/pages/information-professionals.aspx (accessed Sep 2011).

16 Heart Foundation. Career development fellowship: instructions to applicants. 2011. Melbourne: Heart Foundation, 2011. http://www.heartfoundation.org.au/ SiteCollectionDocuments/Career-development-fellowship-instructions.pdf (accessed Aug 2011).

17 Heart Foundation. Heart Foundation Pharmaceutical Roundtable members. Melbourne: Heart Foundation, 2011. http://www.heartfoundation.org.au/ research/pharmaceutical-roundtable/Pages/current-members.aspx (accessed August 2010).

18 Rothman DJ, McDonald WJ, Berkowitz CD, et al. Professional medical associations and their relationships with industry: a proposal for controlling conflict of interest. JAMA 2009; 301: 1367-1372.

19 National Institutes of Health. A guide to preventing financial and non-financial conflicts of interest in human subjects research at $\mathrm{NIH}$. Washington: $\mathrm{NIH}, 2007$. http://ohsr.od.nih.gov/New/COI_GUIDE_02-07.pdf (accessed Sep 2011).

20 Shaneyfelt TM, Centor RM. Reassessment of clinical practice guidelines: go gently into that good night. JAMA 2009; 301: 868-869.

21 National Institute for Health and Clinical Excellence. A code of practice for declaring and dealing with conflicts of interest. London: NICE, 2010. http:// www.nice.org.uk/media/0B2/B6/DeclaringDealingConflictInterestOct08.pdf (accessed Aug 2011).

22 National Institute for Health and Clinical Excellence. A code of practice for declaring and dealing with conflicts of interest. London: NICE, 2010. http:// www.nice.org.uk/media/0B2/B6/DeclaringDealingConflictlnterestOct08.pdf (accessed Sep 2011).

23 National Health and Medical Research Council. A guide to the development implementation and evaluation of clinical practice guidelines. Canberra: NHMRC, 1999. http://www.nhmrc.gov.au/_files_nhmrc/publications/ attachments/cp30.pdf (accessed Aug 2011).

24 National Health and Medical Research Council. NHMRC standards and procedures for externally developed guidelines. Canberra: NHMRC, 2007. http:/ /www.nhmrc.gov.au/_files_nhmrc/publications/attachments/nh56.pdf (accessed Aug 2011).

25 Kendall T, McGoey L. Truth, disclosure and the influence of industry on the development of NICE guidelines: an interview with Tim Kendall. BioSocieties 2007; 2: 129-140. 